\title{
LA PÁJARA PINTA: LA HISTORIA OLVIDADA DE UN PAÍS, DE UNA MUJER
}

\author{
Evelyn Valdivieso Ruíz ${ }^{l}$ \\ Universidad EAFIT, Colombia
}

\begin{abstract}
Resumen: En una era de post-conflicto, cuando surgen las voces de las víctimas, a menudo condenadas al olvido, este artículo propone el análisis de una novela colombiana que funciona como un ejercicio de mnemotecnia y una afirmación subversiva de la experiencia femenina de la Historia: Estaba la Pájara Pinta sentada en el verde limón de Albalucia Ángel (1975). Basado en la teoría del trauma, este análisis se centra en la fragmentación temporal, la distorsión corporal y el desplazamiento semiótico del paisaje natural como elementos estilísticos que encarnan la realidad de la mujer campesina involucrada en La Violencia, un episodio de la historia colombiana que ha dejado marcas indelebles no sólo en las muchas de sus víctimas, sino también en los libros de historia y en la literatura. El presente artículo explora entonces cómo la narrativa de La Pájara desafía los discursos oficiales políticos y literarios que invitan al olvido.
\end{abstract}

Palabras clave: Historia; victimas; olvido; experiencia femenina; discurso oficial.

Recibido: 19 de febrero de 2019

Aprobado: 10 de abril de 2019

\section{LA PÁJARA PINTA: THE FORGOTTEN HISTORY OF A COUNTRY, OF A WOMAN}

\begin{abstract}
In a post-post-conflict era, when the voices of the victims, often condemned to oblivion by patriarchal politics, start to emerge, this paper proposes the analysis of a Colombian novel that functions as a mnemonic and subversive affirmation of the feminine experience of History: Estaba la Pájara Pinta sentada en el verde limón by Albalucia Angel (1975). Grounded on the theory of trauma (but not limited to it), this analysis focuses on the temporal fragmentation, the bodily distortion, and the semiotic displacement of the natural landscape as stylistic elements that embody the reality of the peasant
\end{abstract}

${ }^{1}$ Docente de Inglés del Departamento de Idiomas de la universidad EAFIT. Correo electrónico: evelyn.v.ruiz@gmail.com 
woman involved in La Violencia, a piece of Colombian History that has left indelible marks not only upon the many of its victims, but also in History books and upon its literature. This article explores, thus, how La Pájara Pinta challenges the official political and literary discourses that invite to oblivion.

Keywords: History; victim; oblivion; feminine experience; official discourse.

\section{La Pájara Pinta: la historia olvidada de un país, de una mujer}

La violencia en Colombia es tan amplia y tan compleja que cuando se habla de ella en singular, la historia se queda incompleta. Así, solamente en el siglo XX podemos distinguir entre una violencia partidista, guerrillera, mafiosa, política, paramilitar, y por supuesto la creciente violencia desorganizada (Patiño, citado en Tobar Torres 10). En esta pluralidad, la Historia oficial puede apenas contener todas esas formas de violencia vividas a nivel social e individual. Uno de esos tantos episodios históricos violentos corresponde, a falta de una mejor palabra que lo contenga, a La Violencia (1948-1960), período sangriento y complejo de nuestra historia que se desencadena con el asesinato del candidato presidencial del partido liberal Jorge Eliécer Gaitán y termina con el establecimiento del Frente Nacional. Pese a la generosa documentación existente en libros, fotografías, documentos y archivos oficiales, la historia de esta violencia no recoge las voces ni las experiencias de quienes la vivieron desde el campo, desde su género.

Pareciera entonces que La Violencia hubiera afectado no solo los cuerpos de las víctimas que quedaron tiradas en las calles, ni los trenes condenados al fuego, ni las ventanas y puertas violentadas, sino también la Historia misma, que mocha, tuerta, y medio muda a duras penas logra transmitir esa realidad del país. El verdadero impacto que los atroces eventos tuvieron en el individuo parecen escapársele a los reportes, a las estadísticas, y a los noticieros por más amarillistas que fueran. La Violencia escapa la representación y se convierte en una crisis que las palabras apenas pueden capturar; "La verdad se vuelve más grande y más extraña que la ficción misma" (Blau 5).

El lenguaje literario, sin embargo, abre espacios para la expresión y la divulgación de las violaciones y el sufrimiento de sus víctimas. De 
hecho, algunas plumas han logrado plasmar lo que la política y hasta la misma crítica literaria han relegado al olvido. Se trata de una literatura que se preocupa por encarnar en su narrativa las experiencias traumáticas de las víctimas de esa historia violenta colombiana, por exorcizar el pasado traumático de una nación, y por darle una voz a la memoria individual que el discurso oficial ha silenciado: La Pájara Pinta de Albalucía Ángel (1975). Para ello, el análisis aquí propuesto parte de la teoría del trauma con el fin de desvelar los elementos que la violenta historia colombiana ha dejado impresos en esta novela y aquellos que ella revela de la historia. El argumento se centra particularmente en la vivencia femenina de La Violencia, historia que Albalucía Ángel le arrancó durante años de investigación a los archivos empolvados de esta época y que resucita en esta novela.

Con esto en mente, las cuestiones a analizar son, en primer lugar, las estrategias narrativas de la novela; cómo logra su autora hacer de ella un objeto mnemónico que permite la articulación de una memoria individual y colectiva de los hechos. En segundo lugar, este artículo analiza cómo esta articulación propone una visión crítica de la Historia y el discurso oficiales. Para esto, se propone una lectura de la novela que gire alrededor de tres ejes: la temporalidad, la representación del cuerpo femenino y el empleo de elementos naturales como forma de encarnación del inefable dolor.

Este enfoque, aunque se informa de la teoría de trauma tradicional y postmoderna, no se limita a esta. No obstante, este artículo comienza con una breve reseña sobre la teoría del trauma, su historia, y su influencia en la literatura con el fin de contextualizar al lector y de justificar dicha teoría como base de análisis.

\section{Trauma}

La teoría del trauma parece la más adecuada para este análisis ya que estudia cómo una herida histórica afecta la realidad inmediata de la víctima, cómo la historia y el presente se hacen uno solo, y cómo el verbalizar dicha experiencia puede resultar en el alivio de la víctima, en su "cura." De acuerdo con Cathy Caruth, experta y pionera estadounidense en el tema, la literatura y la teoría del trauma se complementan la una a 
la otra por lo que un análisis que comprenda ambas nos permitiría "ver y escuchar" las experiencias que una historia violenta ha dejado en la individualidad de sus víctimas.

Del griego $\tau \rho \alpha \tilde{\mu} \mu \alpha$ que significa "herida" (Caruth 3), el término Trauma se utilizaba en sus comienzos solo para designar un daño infringido al cuerpo. No obstante, en las últimas décadas, el término ha permeado otros campos del conocimiento, particularmente las ciencias humanas. Durante la primera guerra mundial, trauma se hizo popular en la naciente psicología de posguerra y se definió como una lesión en la psique causada por una experiencia que abrumaba las formas de adaptación humana a la vida ordinaria. Según la psiquiatra y especialista estadounidense Judith Herman,

A diferencia de las desgracias comunes, los acontecimientos traumáticos generalmente implican amenazas a la vida o integridad corporal, o un encuentro personal cercano con la violencia y la muerte. Ponen a los seres humanos frente a frente con las extremidades de la impotencia y el terror, y llaman a dar respuesta a la catástrofe (24).

Después de la Segunda Guerra Mundial, las ciencias humanas comenzaron a estudiar el trauma desde una perspectiva menos individualista y se concentraron en el trauma causado a las masas. En sociología, por ejemplo, el concepto de trauma se ha vuelto inherente al estudio de las catástrofes y el terror político que amenazan la sensación de seguridad de una comunidad o grupo. El sociólogo estadounidense Jeffrey C. Alexander, en su estudio sobre el "trauma cultural", también conocido como "trauma de masas", explica que este ocurre cuando "los miembros de una colectividad sienten que han sido sometidos a un acontecimiento horrendo que deja marcas indelebles en su conciencia de grupo, marcando sus recuerdos para siempre y cambiando su futura identidad de manera fundamental e irrevocable" (6).

Muchas de estas experiencias, además de sacudir la identidad de un grupo o sociedad, se convierten en narrativas que buscan la responsabilidad y comprensión de la sociedad y a veces hasta el mismo cambio político. Y es entonces cuando el trauma y la literatura se encuentran. 
Pero de esta unión surge inevitablemente la pregunta de si realmente se puede expresar lo inefable y de cómo hacerlo. Para Caruth, ya que la literatura y la psicología se preocupan por "la compleja relación entre saber y no saber" ${ }^{2}$ (2), el lenguaje poético o literario establece un diálogo con el trauma que el lenguaje ordinario o la referencia directa a la historia no pueden. En consecuencia, "el lenguaje no lineal y literario se convierte en el medio por el cual lo indescriptible puede expresarse" (ibidem). Caruth también sugiere que es a través del diálogo que el trauma establece con la literatura que la "herida" causada por el evento catastrófico puede en realidad ser verbalizada integralmente en una comprensión consciente y lúcida de la misma:

[la literatura de trauma] es la historia de una herida que grita, que se dirige a nosotros en el intento de comunicarnos una realidad o verdad que no está disponible de otra forma. Esta verdad, en su tardía aparición, no puede estar ligada sólo a lo que se comprende, sino también a lo que queda inexplicado en nuestras propias acciones y en nuestro lenguaje (4).

En una línea similar, Allen Gibbs afirma que la expresión artística es un modo de catarsis. Dado que trata de experiencias que no se almacenan como cualquier recuerdo regular, no es de extrañar que el lenguaje artístico utilizado para expresarlas venga en "segundo orden, silenciado, velado, de formas distorsionadas, equívocas o comprometidas" (citado en Ganteau 10). Así, estas narrativas se ocupan de materializar los síntomas experimentados por la víctima mediante la distorsión del tiempo, del lenguaje, y de los espacios. Algunos ejemplos de las estrategias utilizadas para alcanzar estos efectos incluyen la polifonía, la repetición, y el cifrado. Estas estrategias narrativas fueron innovadoras y eficaces en la literatura del Holocausto, Afroamericana, feminista, y la de otras minorías, convirtiéndose en un elemento básico de la literatura de trauma.

Caruth sugiere que, debido a que la literatura, al igual que el psicoanálisis, habla de y a través del trauma, esta clase de narrativas también permiten a los lectores conectarse con las historias de dolor y

${ }^{2}$ Esta idea de "no saber" es, Caruth explica, todo aquello que no se comprende completamente de esa experiencia traumática, y que por consecuencia no se puede verbalizar. 
pérdida de otros mientras "escuchan" sus heridas. En resonancia con Jacques Lacan y Margueritte Duras, Caruth declara que escuchar el discurso de otro, un discurso que sigue siendo enigmático y que exige una escucha y una respuesta, constituye el nuevo modo de leer y de escuchar, acciones que "el lenguaje del trauma y su muda repetición del sufrimiento, exigen profunda e imperativamente" (9).

Sin embargo, cabe anotar que actualmente las formas de la literatura de trauma tradicional presentan ciertas limitaciones, particularmente cuando se trata de analizar la literatura postcolonial o cualquier literatura no enmarcada en la cultura occidental -que es donde estas teorías nacen y se explican. En un movimiento de descolonización del término "literatura de trauma", autores como Sonya Andermahr, Bryan Cheyette, StefCraps, Alan Gibbs y Larissa Allwork invitan a una lectura más abierta de la ficción que se acerca a eventos históricos traumáticos.

Esta aproximación postmoderna a la literatura de trauma abarca no sólo la víctima sino también a la experiencia del agresor y del testigo, así como otros elementos anteriormente ignorados. Entre las estrategias narrativas que estos autores remarcan están el uso de una memoria detallada más que del olvido (como es típico de la literatura de trauma tradicional), y la recurrencia al naturalismo para incluir en el paisaje el impacto de los eventos traumáticos. Esta teoría básicamente invita a ver la literatura de trauma fuera de los marcos establecidos por el canon europeo, y se abre a otros espacios. En el presente análisis de La Pájara Pinta se evidencian estrategias de ambas tendencias (la tradicional y la postmoderna) particularmente en tres aspectos: la rota pero detallada memoria de una niña que rompe con la temporalidad de su historia, la dislocación del cuerpo femenino y la inseparabilidad de la memoria y la experiencia corporal con el paisaje colombiano.

\section{Temporalidad}

La compleja relación entre el acontecimiento histórico traumático y la vivencia del mismo es precisamente de lo que se ocupa la literatura de trauma. Según Caruth, este no radica en el suceso, sino en los síntomas, en su tardía repetición. Esta propiedad, imitada por la literatura, toma la fuerza de una literalidad que "lo hace resistente a las estructuras narrativas tradicionales y a las temporalidades lineales" (Whitehead 
5). En otras palabras, la temporalidad debe destruirse para acceder al evento latente, a su historia.

Durante mucho tiempo, la literatura se ha preocupado en representar el impacto del trauma "imitando sus formas y síntomas" (Whitehead 3). Una de las maneras más comunes de apartarse de la linealidad y transmitir el sentido de latencia es el desplazamiento cronológico. Más específicamente, Whitehead escribe que las narrativas traumáticas representan la dislocación temporal característica de la experiencia traumática al construir un presente ensombrecido por el pasado (27). El tiempo se deforma para representar la incomprensibilidad de los acontecimientos traumáticos, el efecto obsesivo de la memoria traumatizada, y otros síntomas experimentados por la víctima. El especialista francés Marc Amfreville, por su parte, afirma que las narrativas son auténticas narrativas traumáticas cuando "describen un violento avance en la conciencia de tal naturaleza que permanece inasimilable en el momento de su aparición, pero también cuando se observa un fenómeno de latencia" (citado en Ganteau 162). Para Laurie Vickroy, especialista estadounidense en estudios de trauma, este tipo de narrativas "internalizan los ritmos, los procesos y las incertidumbres de la experiencia traumática" (3), y por lo tanto "se apartan de la frase lineal convencional" (6).

El objetivo de esta primera parte es explorar cómo el tiempo se fracciona y se reconstruye en la novela, y cómo, al hacerlo, se anatomiza la voz de las víctimas y se representan algunos de los síntomas que ellas experimentan mucho después del evento detonador. Entre las estrategias más notables están la fragmentación y la sobreexposición de la Historia pública con la historia personal. Este último es uno de los rasgos más característicos de la literatura de trauma ya que estas narrativas encarnan no solo la complejidad de la memoria individual sino su necesidad de encontrarse en la memoria pública para adquirir sentido.

\section{Fragmentación en La Pájara Pinta}

El argumento de la novela tiene como epicentro la vida de Ana, una niña pereirana de familia adinerada, cuya infancia y adolescencia se ven marcadas por los casi veinte años que duró La Violencia. De hecho, 
el punto de partida de su historia es también el evento detonador de este periodo histórico: el asesinato de Jorge Eliécer Gaitán el 9 de abril de 1948. El memorable evento, sin embargo, no es ficcionalizado sino narrado en la voz de varios protagonistas: Joaquín Estrada Monsalve, Carlos Lleras Restrepo, Berta Hernández de Ospina, "una licencia literaria que, paradójicamente, hace que la realidad parezca ficción" (Mejía 3). Las piezas que componen la historia de Ana son presentadas por múltiples voces, formales e informales, documentos históricos, cartas, nombres de marca, referencias cinematográficas, etc. Su historia se fragmenta, se sobrepone y se complementa con ese sangriento periodo de la Historia Colombiana.

Ángel utiliza una narrativa de modo libre-asociativo que le permite a su narrador-protagonista moverse a través de la memoria tanto personal como pública en un aparente desorden de ideas y recuerdos. Sin embargo, el rasgo más sobresaliente de su narrativa es la fragmentación que resulta de la polifonía y de su vaivén entre el presente y el pasado. De hecho, en la primera parte de la novela, que funciona como prólogo, la escritora introduce varios de los elementos cruciales para fragmentar la narración: la memoria, la búsqueda del significado en el laberinto del pasado, y la polifonía. Según la profesora colombiana Aleyda Gutiérrez, el caos que resulta de esta heteroglosia y del caos cronológico es una respuesta a la realidad del país, realidad que no cabe en una narración lógica ni tradicional:

Su consigna parece apuntar a la transgresión del relato tradicional, no se puede seguir narrando de manera lineal, ordenada y lógica porque la realidad ya no es así. La realidad ahora es fragmentada, ilógica y violenta, por ende, la escritura debe ser fragmentada, ilógica y violenta (Gutiérrez 77).

Esta polifonía se logra a través de técnicas como el préstamo documental en forma de citas directas, con o sin atribución, y repetición, a menudo con variación. Según Amalia Gladhart, la memoria de Ana tiende a tener un carácter integral: "Los recuerdos de Ana se expresan a menudo a través de exhaustivamente largas oraciones que buscan 
incluirlo todo, para resaltar la abrumante acumulación de recuerdos del narrador" (Gladhart 93).

Así, la voz de Ana, al ser parcialmente desplazada por otras voces, también se ve desplazada y repetida por otros puntos focales: las historias de los campesinos afectados por La Violencia, citas intercaladas de los relatos publicados del 9 de abril de 1948, y una prolongada digresión sobre la fundación de la ciudad de Pereira también se añaden a la mezcla" (Ibid). Este desplazamiento relativo de Ana por numerosas voces, documentos y narraciones incluidas en la novela es lo que produce su efecto más notable: una acumulación de memoria y distorsión que, en su conjunto, crea una historia alternativa de la época que representa y cuestiona la posibilidad de producir tal historia en absoluto. Pero el propósito de la memoria no es la purgación, ni una reconstrucción de la historia para que todo sea revelado y comprendido. De hecho, mucho queda sin explicación, tanto para el narrador como para el lector, y la memoria refleja en su defectuosidad y circularidad la situación atrapante del suceso que intenta representar.

Haciendo eco de María Mercedes Jaramillo, el estilo fragmentario de las novelas puede leerse como "el mecanismo mnemotécnico anunciado por la autora en el epígrafe" y que recrea la ignorancia del pueblo colombiano, "que solo recibe retazos de noticias o presencia episodios aislados que no logran formar un corpus coherente que permita entender el proceso social y político que se está viviendo" (212). Gabriela Mora, por su parte, sugiere que la estructura de la novela, "constituye una especie de estructura alegórica del caótico periodo de historia colombiana en que se enmarca" (73). Así, la fragmentación de la narrativa (en tiempos y voces) refleja no solamente el caos de una historia pública inconexa, nunca entendida por completo, sino también la memoria fragmentada de la protagonista, que sólo tiene acceso a documentos censurados, palabras indefinidas e informes de segunda mano.

Al encarnar los procesos y ritmos de la memoria, la narrativa de Ángel no solo tiene que incluir otras voces sino también moverse fluidamente (y a veces violentamente) por diferentes tiempos gramaticales. Así, la voz de Ana comienza con un diálogo en el presente y se ve drásticamente 
interrumpida por otras, donde el pasado va y viene sin darle al lector previo aviso. Mientras que la escritura tradicional nos presenta el tiempo como una sola línea que tiene principio y fin, la narrativa de Ángel nos ofrece varios hilos que el lector debe tejer para recrear la historia.

Este vaivén en el tiempo crea a su vez una estructura circular que se establece al abrir un evento, sea en la vida de Ana o en la de otros personajes, y se retoma sólo más tarde en la novela para explicarse o terminar de desarrollarse. Un buen ejemplo de esta circularidad se da en la escena del abuso sexual que Ana sufre de niña. Inicialmente la escena aparece como un recuerdo vago, pero cuando Ana empieza a experimentar su sexualidad con su amiga Julieta, esta escena vuelve y toma sentido. Esta escena, como muchas otras, aparecen y reaparecen completando en cada resurgimiento la historia de Ana o la de otro personaje. El movimiento circular del tiempo funciona no sólo como metáfora de sus personajes estancados en el pasado, o de un pasado que rehúsa a irse, sino que también performa los procesos de la memoria, sobretodo lo de una memoria infantil cuya psique no puede darle sentido a lo que ha experimentado.

Así, La Pájara Pinta fragmenta la narración por medio de un acercamiento multifocal a la historia y por medio de la repetición de varias escenas que no le permiten al presente de los personajes desenvolverse en una sola línea. La narrativa de Ángel despedaza el sentido y la temporalidad de los hechos para representarlos dentro de su desorden y su ausencia de sentido.

\section{Un cuerpo reducido al sexo, un cuerpo ausente}

Junto a la voz de Ana emergen también otras voces femeninas que reconstruyen historia la vivencia de la mujer colombiana durante La Violencia. Estas voces, aunque hablan de cuerpos violentados y silenciados, también se convierten en objeto de subversión, de resistencia al olvido. Según Guerra-Cunningham, es en el contexto de una historia malentendida y desordenada que lo "doméstico y femenino adquieren un valor contestatario, no solo con respecto a los parámetros de las construcciones culturales sobre las cuales se construye la Nación sino también como inscripción subversiva del cuerpo de la mujer, de su 
praxis doméstica y de su vivencia de la Historia" (Citada en Gladhart 15). Esta presencia subversiva de lo femenino se hace evidente en varios niveles: en el énfasis repetitivo de las sensaciones corporales de los personajes femeninos, en la representación femenina de activismo político, pero también en la identificación de otros personajes femeninos con el trabajo doméstico y con el mantenimiento del hogar y la familia como los únicos roles que pueden garantizar un poco de seguridad.

Personajes como Sabina, la madre de Ana, y las monjas del colegio representan perfectamente este rol designado para ellas por una sociedad patriarcal: siempre enclaustradas, cubiertas en trajes "apropiados," alejadas de la política y cumpliendo con labores domésticas y religiosas: Sabina, por ejemplo, se presenta "imperturbable, olímpica, eficiente, cambia el agua al florero. Tira las flores que ya están ajadas. Pone las otras que cogió muy temprano [...] Les hace una ranura a filo de tijera. Acomoda de nuevo. Rocía un poco los pétalos, con una brizna de agua" (48). Doña Chepa, por su parte, es una ejemplar católica que va a la iglesia "con un vestido azul de Prusia sin perderse jamás una matiné" (147). Estos personajes femeninos pulcros, son los únicos que se mantienen "a salvo" de la violencia y objetivación moral y sexual de la que los otros personajes femeninos son víctimas.

Por otra parte, los personajes femeninos que protestan o salen de su rol son frecuentemente objetivados y "condensados metonímicamente a su sexo" (Osorio 75). Su sexo se convierte un objeto receptor y un objeto para afirmar la masculinidad y el poder patriarcal de otros personajes. El cuerpo de Ana, por ejemplo, es utilizado en la búsqueda masculina de Lorenzo: "y te miré los ojos de ese color extraño, brillantes por la fiebre, mientras seguía diciendo cosas y disponiendo de mi miedo como si en realidad lo que tuvieras en la mano fuera otra vez mi sexo descubierto y penetrando en él, como buscando ¿Qué buscabas?” (9). Aunque estas relaciones son consentidas y rompen con la tradición de su hogar, la experiencia sexual de Ana con Lorenzo no es satisfactoria ni recíproca. Ella juega el papel pasivo de dar soporte y placer en los momentos de fiebre y delirio que Lorenzo sufre luego de haber sido torturado por la policía. 
Estas relaciones sexuales con Lorenzo también revelan una relación de posesión: "disponiendo de mi miedo como si en realidad lo que tuvieras en la mano fuera otra vez mi sexo descubierto" (ibidem) y es probablemente por este rol pasivo que se le impone en el sexo que desde su primera vez con Lorenzo se produce un flashback de la violación que había sufrido cuando apenas era una niña. El abuso sexual sólo se describe más adelante, como un incidente nunca completamente entendido y sobre el que Ana nunca habla con nadie; ella solo recuerda ponerse de pie "con gran esfuerzo, porque tenía el cuerpo magullado, y entonces entendió lo que le había sucedido a Saturia aquella vez" (259). Este rol aplastante del personaje masculino, incluso en una relación consentida como la que Ana tiene con Lorenzo, refleja la situación de la mujer inscrita a la sociedad patriarcal de la época.

La sexualidad de Ana está atrapada en la violencia como periodo histórico y el recuerdo parcial de sus vivencias personales. El recuerdo de su sexualidad se confunde entonces entre sentimientos de amor, placer y dolor. Frecuentemente, su cuerpo y el de sus amigas se ven simplemente aplastados, violentados y sometidos a la voluntad masculina de ese entonces.

\section{La violación como forma de violencia patriarcal y política}

La forma más evidente en que la novela muestra el rol patriarcal aplastante con respecto al cuerpo femenino se hace a través de las múltiples alusiones al abuso sexual de mujeres, particularmente la escena de violación de Saturia y de Ana. La primera se narra en tercera persona y aunque los ojos que observan son inocentes (son niños), la violación se muestra de todas formas en toda su obscenidad y violencia:

Vieron al hombre y a Saturia, o mejor, las piernas de Saturia porque el cuerpo del hombre la cubría y Saturia chillaba ya no más, un poquito no más, decía él, no seas malita, te voy a regalar una muñeca grande desas que tiene don Severiano en la vitrina, y Saturia que no, que yo no quiero, y otra vez con los gritos, y entonces el hombre le taponó la boca con la ruana $[. .$.$] cuando empezó a quejarse como si le doliera también$ algo, a refregarse como un desesperado contra la pobre de Saturia, que se calló de pronto y comenzó a hacer bizcos, hasta que al fin dio un alarido y los ojos en blanco, muy abiertos, y el hombre entonces se solivió 
un poquito como si fuera a levantarse pero en lugar dio tres enviones más, con mucha fuerza, y después quedó inmóvil [...] Se levantó de encima de Saturia, que se quedó en el suelo sin moverse, y fue cuando le vieron la sangre que le bajaba por las piernas. Apenas el hombre se terció el machete, se templó el cinturón, y comenzó a perderse por entre el cafetal, Saturia se volteó bocabajo y se puso a llorar (72).

En esta escena el silenciamiento de Saturia por parte del peón simboliza, según Myriam Osorio, el silenciamiento de la mujer campesina y pobre. Sin embargo, aunque Saturia no tenga voz, Ángel se asegura de que su historia sea narrada en tercera persona por quienes la vieron y también sea "sentida" por otras mujeres como ella: "Ana, quien, mientras observa escondida con los otros niños, temiendo ser descubiertos, "siente" en su propio cuerpo la opresión de la que Saturia está siendo víctima: "sentía la camisa pegada a las costillas y un estremecimiento en todo el cuerpo" (72).

Las imágenes de abuso sexual que Ángel "salpica" en toda la novela, además de llamar la atención sobre la violación de una población indefensa de niñas y jóvenes, también resalta que esta forma de violencia rompe con las clases sociales, convirtiéndose así en un problema de género. Ana, pese a ser "hija de patrones" también puede ser violada como Saturia, como cualquier otra niña campesina. "Este hecho, aunque no es verbalmente compartido entre las dos mujeres, (Saturia no sabe que Ana fue testigo de su violación y tampoco sabe que Ana fue violada) las "hermana" y constata que, a pesar de sus diferencias de clase, sus vidas personales están condicionadas por estructuras sociales de carácter patriarcal y violento" (Osorio 78). Este rompimiento de clases sociales se hace aún más evidente cuando más tarde Ana describe la violación de la que es víctima y nos presenta una escena que hace eco de la violación de Saturia.

Las escenas son similares en que las dos se dan a campo abierto, el agresor es un peón que ellas conocen, ambas niñas intentan oponerse física y verbalmente, pero sus agresores, superiores en edad, tamaño y fuerza les tapan la boca "con la ruana." Luego, ambos hombres se ponen la ruana y se ajustan la correa y el machete, todos símbolos de masculinidad típicos en la Colombia rural de aquella época. Finalmente, 
ambas escenas terminan con sus víctimas tiradas en el suelo en la misma posición y actitud: "Saturia se volteó bocabajo y se puso a llorar" (72) y Ana "se volteó de cara al suelo porque no pudo más de pesadumbre, y se deshizo en lágrimas, en gemidos dolientes, y así lloró y lloró" (184). No obstante, Myriam Osorio resalta que la escena de Ana deja ver mucho más desde la perspectiva de la víctima. Ana, aunque inicialmente no entiende lo que ocurre, describe nítidamente el dolor físico y psicológico que vive en el momento.

[...] y él le abría las piernas de a poquitos, buscaba con los dedos [...] ¡yo la maté...!, yo fui..., soltando el alarido porque la estaba hurgando hasta por dentro. Así no, ique me duele! No, no te duele, te voy a hacer pasito. Pero la penetraba con violencia, y ella sentía las manos sudorosas sobre su cuerpo tenso, ¡no!, iyo no quiero...! [...] no te hago daño, ¿ves? Y se movía despacio, pero eso sí dolía y ella, ¡no quiero...!, pero él, no te hace daño, quietecita, y le tapó la boca para que no siguiera, ¿te gusta así...?, qué rico, y era como si la estuvieran abriendo a cuchilladas (183).

La alusión que Ana hace al falo de Alirio como un cuchillo que "la abre a cuchilladas" corresponde al vocabulario que en la Colombia de la época de la Violencia se había convertido en el diario vivir. El vocabulario nacido de la época es el único vocabulario del que Ana dispone para narrar esta experiencia que, como la historia nacional, ella no alcanza a entender todavía. La historia nacional se mezcla una vez más con la personal, pero en este caso a un nivel más íntimo, más corporal. Así, el cuerpo femenino en la Pájara Pinta se convierte en un objeto de violencia patriarcal. Mujeres son violadas por razones políticas o inferencias sociales entre hombres. Alirio, por ejemplo, es consciente de la diferencia de clases: "yo no me voy a meter en un enredo, no creas que no distingo. Yo soy un peón y tú eres hija de patrones, pero no quita que te puedo decir que eres muy linda, ¿no?” (182), y sin embargo su estatus no le impide el eventual abuso sexual ni su impunidad. Igualmente, Ana alcanza a leer en un recorte de periódico que ni ella ni Sabina son las únicas en sufrir estos atropellos, que la violación de mujeres se da como forma de "atacar" la oposición. Según Osorio (78), "en el marco del contexto histórico de la violencia 
ellas son además objetos a través de los cuales se cobran las venganzas partidistas:"

La policía política inicia su intervención con vejámenes, golpes e insultos. Después roba, incendia y asesina; a la postre viola, estupra y remata en actos nefandos. Primero actúa en forma reservada; posteriormente afrenta sus víctimas ante progenitores, hermanos y aun menores de edad. A poco andar violenta chiquillas de ocho y menos años hasta matarlas, [...] Más adelante se registra el caso monstruoso de violaciones colectivas cuando una sola mujer es arrojada a la tropa, con abierta incitación al delito por algunos oficiales psíquicamente lesionados [...] Cierto oficial incursionaba para traer doncellas quinceañeras a la grupa de los caballos y después de algunos días entregarlas por turno y sin honor a la suboficialidad cómplice que las negociaba por precio irrisorio con la soldadesca sin moral por el ejemplo del jefe. [...] En el asalto de Miraflores, donde una paralítica de dieciocho años de nombre Eugenia Barreto, fue atropellada por quince de los bandidos; como no se pudiera mantener de pie fue amarrada a la columna de la casa y luego quemada viva. Asimismo [...] una niña de trece años fue violada por los bandidos en presencia de las gentes. En el Guarumo (municipio de Caucasia, Antioquia), asesinan una niña de ocho años y luego le introducen en las partes pudendas, los genitales cercenados a su propio padre. [...] Impúberes de doce y trece años aparecen violadas infamemente por cinco y diez y hasta quince forajidos y cobardes. Las mujeres en miles y miles de casos, deben pagar con el honor la cuota que les cobra la violencia, al extremo de que apenas se verifica asalto o comisión que las deje ilesas (188).

La violencia que Ana y otras mujeres (y niñas) temen, pese a no entender la situación, se caracteriza por la violación y la mutilación. El enfoque en la corporeidad de las amigas de Ana, Valeria y Julieta, en la apariencia, preparación y tratamiento de sus cadáveres encarna vivamente la fragilidad de sus cuerpos y el peligro al que las otras niñas corrían si se adherían a las reglas: "si no se portaban bien tarde o temprano les iba a suceder lo mismo o algo así" (65). Pero Ángel nos muestra un cuerpo femenino destinado a ser violentado sin importar su edad, comportamiento o su convicción política. El cuerpo inerte de Valeria, por ejemplo, representa una mujer adulta, una mujer activista, mientras que el de Julieta representa una niña cuyos cortos años no le 
permitían inclinarse hacia ninguna ideología política, y sin embargo ambos han sido fatalmente atropellados y violentados. La diferencia sólo se desvela en la presentación de los cadáveres.

Así, Julieta, atropellada por un tranvía, es presentada por las monjas como un ejemplo cautelar: "Se la tuvieron que amputar, dijo con cara de si no se portaban bien tarde o temprano les iba a suceder lo mismo" (65). El cuerpo sin vida se ve impecable: "No parece una muerta. Lo primero que ve es que tiene las dos piernas, las medias de hilo blancas, los zapatos, el uniforme de gala lo alargaron casi hasta los talones, y como? No se le nota, O lo mejor no es cierto, y lo que les dijo Rudolfina fue nada más por asustarlas" (250). El cuerpo de Julieta, no obstante, presenta una imagen bastante contradictoria: por un lado, de lo que podría sucederles a sus compañeras de clase el destino que aquellas que se escaparan del colegio y, por otro, de un icono perfeccionado de inocencia infantil -su cuerpo amputado es "remendado," su muerte se maquilla de reposo. La pulcritud en que se presenta el cuerpo de esta víctima esconde, como el silencio de Ana y Sabina, el ultraje que sufrieron en la Colombia de La Violencia.

El cuerpo de Valeria, por el contrario, no recibe tal cuidado: “¿Reconoce el cadáver?, preguntó el policía, que levantó la sábana mugrosa, dejando al descubierto tu desnudez violada y aterida: tu cuerpo desvalido, que nunca, como esa vez, amé yo tanto" (225). En este caso, la violencia no se esconde ni se maquilla porque tiene un propósito: el de dar testimonio del poder que la policía y el gobierno (ambos representados por el género masculino) tenían frente a ellas, como ciudadanas y como mujeres. Al igual que Julieta, el cadáver de Valeria se presenta como una advertencia y como un ideal: por una parte, además del estado sucio y maltratado del cuerpo, Ana escucha las amenazas verbales del policía que la observa burlona y obscenamente mientras ella reconoce el cadáver de su amiga. Por otra parte, la muerte en estas condiciones le da a Valeria y sus convicciones un grado de heroísmo, lo que incrementa el amor y admiración de Ana por este personaje.

Este énfasis de la novela en la violencia contra el cuerpo femenino muestra la insistencia de Ángel en que "el peor crimen durante la Violencia fue la violencia sexual que las mujeres colombianas tuvieron 
que sufrir, sin importar su ideología política o edad" (García Pinto, citado en Gladhart 97-98). Ángel recrea en el cuerpo de estos personajes otra forma de violencia que debido al silencio al que fue sometido su género no abarca los libros de historia, lo que insinúa una subversión al discurso y la historia oficiales.

Por último, pero no menos importante, cabe mencionar que esta subversión femenina es política. Al reconocerse en la experiencia corporal de otras mujeres y niñas en la narración, el cuerpo de Ana, el cuerpo femenino, se convierte en un espacio político. Según Judith Butler:

Lo personal es político, por tanto, implícitamente político, puesto que está condicionado por estructuras sociales compartidas, pero lo personal también ha sido inmunizado contra el desafío político en la medida en que las distinciones público-privadas perduran. Para la teoría feminista, lo personal se convierte en una categoría expansiva. Mi situación no deja de ser mía sólo porque es la situación de otra persona, y mis actos, aunque individuales, reproducen sin embargo la situación de mi género y lo hacen de varias maneras. (406)

La dualidad de lo personal y político, lo privado y lo público se representan más que en un cuerpo ultrajado, en la identificación de un cuerpo con la consciencia de otro (Ana). Así la representación corporal de la mujer se convierte en un espacio donde estas dualidades de dibujan y el silencio se rompe. Veamos ahora cómo estas dualidades se reafirman través de la identificación del personaje femenino con un animal que representa ambos libertad y encierro: "el pájaro."

\section{El pájaro como objeto correlato}

Como ya se había mencionado, algunas narraciones integran elementos de la naturaleza para representar la complicada relación que el presente de la víctima tiene con un pasado traumático. En el caso de $L a$ Pájara Pinta, uno de los motivos que mejor evidencian esta estrategia es la correspondencia entre la figura del pájaro y las experiencias de Ana. Albalucía Ángel se ayuda de esta relación para establecer una vez más la inseparabilidad entre la Historia pública y la individual. 
El título Estaba la Pájara Pinta Sentada en el Verde Limón no solo hace eco a una canción infantil, sino que trae a colación una palabra que, en el contexto histórico de la novela, está simbólicamente cargada de violencia política: pájaro. Este término, en el "Léxico de la violencia en Colombia" de Publio González-Rodas, se define como "un término original del departamento de Caldas; equivalente a bandido, antisocial, revolucionario, ladrón o sospechoso" (308). En términos históricos generales, "pájaro" era otra forma de llamar a los miembros del partido conservador. Del mismo modo, las palabras relacionadas con este término, como "chulo" (buitre) y "cóndor" también tienen connotaciones negativas relacionadas con la tensión política del momento. "Chulo," por ejemplo, se usaba para referirse a la policía peyorativamente, y “cóndor," el rey de las aves de rapiña, para nombrar a las cabezas grandes del partido conservador.

Interesantemente, en la novela de Ángel, las aves rapaces de $L a$ Violencia son inseparables de las aves presentes en los recuerdos de infancia de Ana, que tienen una connotación mucho más positiva, como el ave a la que alude la canción infantil de la que se inspira el título. Las aves, cuando se describen con la tinta de la historia colectiva aparecen como elementos destructivos, pero cuando aparecen en los recuerdos más íntimos de Ana, especialmente los de su infancia, cuando su juventud no le permitía entender su situación, los pájaros conectan a Ana con un estado natural de libertad y bienestar. Esos momentos de felicidad en que Ana y sus amigas "se vuelan" de la sociedad a la que están inscritas son evidentes en sus travesuras y juegos sexuales (171172). De hecho, en el funeral de su amiga Julieta, Ana piensa en la pájara pinta y cree que es con esta canción que debería decir adiós a su amiga porque "La Pájara Pinta" alude a su felicidad y evoca los mejores momentos que vivieron juntas.

El título de la novela no solo muestra la contradicción detrás del término "pájaro," sino la dualidad, la lucha interna de Ana para encontrar su identidad individual dentro de la historia nacional. El juego de dobles que Albalucía Ángel propone desde el título se refiere no solo a la búsqueda del pasado (infancia) donde la imagen del pájaro es tan optimista como el tono de la rima, sino también al entorno social 
donde la imagen del pájaro se convierte en sinónimo de violencia y terror. "En el título y en toda la novela, infancia y violencia, la historia personal y colectiva se entrelazan" (Gladhart 91). La sobreexposición de la historia personal con la oficial también sirve para cuestionar la memoria pública colombiana que tiende a dejar en el olvido el dolor causado por los hechos históricos violentos; "A nadie le importa que la gente pierde la memoria. Se olvida pasan diez años y es como si no hubiera sido más que aguacero que diluvio que nuestro dejó el país inundado tanto tiempo" (159).

En una forma más estructural, la búsqueda de identidad de Ana también se refleja en el movimiento gramatical el título. Estaba la pájara pinta sentada en el verde limón, presenta al animal en movimiento. El verbo "estar" en su imperfecto "estaba" denota un tiempo nómada, fluido y constante. Según Rossi Braidotti "el tiempo nómada es el imperfecto: es activo, continuo. El estilo nómada se trata de transiciones y pasajes sin destinaciones predeterminadas ni hogares perdidos" (25). En este sentido la pájara del título ya ha emprendido vuelo, pero como Braidotti afirma, el destino es desconocido. Una vez entrados en la obra, el texto nos muestra que la pájara es Ana y que el vuelo emprendido ha sido más bien una búsqueda de identidad dentro de la caótica historia nacional. De hecho, esta es una de las razones por las cuales se categoriza esta novela como una novela histórica y Bildungsroman al mismo tiempo.

Ahora, la alusión al vuelo (no solo por la figura del pájaro mismo sino por el tiempo gramatical que se opone al estatismo) puede interpretarse como augurio de libertad y la posibilidad de escapar. En algunas ocasiones Ana se identifica con este sentimiento de libertad y personifica ciertas posturas o comportamientos del ave: "Julieta... ¡Qué...! ¿Te gustaría ser pájaro? A mí, pues claro: ¿y tú...? ¿A mí?, ipues claro...!" (96), entonces Ana y Julieta se suben a un árbol y cantan como pájaros la canción de la pájara pinta:

¡se romperán la crisma, niñas!, ¡que se bajen de ese árbol...!, seguían cantando a voz en cuello: estaba la pájara piiiinta, sentada en el verde limón, con el pico recoge la coooola, con la pata retoma la flor [...] ¡cero en conducta esta semana!, mientras buscaba entre las ramas a las pájaras pintas, que ya se habían volado. (96) 
En esta escena Ana y Julieta personifican perfectamente al pájaro y consiguen, aunque fugazmente, la libertad que el ave tiene de cantar (de hablar) y de volar (de irse, de "volarse"). En otras ocasiones, sin embargo, Ana hace referencia a este animal para expresar su falta de libertad, tanto moral como física:

¿Y usted no ha ido, no? Qué voy a haber ido, sino me dejan ir más lejos que Cerritos o es que no entiendes lo que te estoy diciendo. Un Sabú sin alfombra voladora, el gato sin sus botas, Aladino sin lámpara, Alicia sin espejo, una imbécil sin alas como cualquier mortal, ¿no lo ves? (46)

Ana se vale de estas comparaciones para verbalizar el encierro y censura que implica ser una joven en una familia católica pudiente que la aleja no sólo de la realidad física sino de la información (por eso es que Ana debe leer el periódico a escondidas).

Expresiones similares de frustración e impotencia aparecen con la ayuda de otra metáfora que sale a flote repetidas veces en la novela "soy un pez en el aire, un pájaro en el agua" (51, 98, 177, 223, Itálicas de Ángel). La imagen mental que sugiere esta expresión, aunque no muestra animales mutilados ni en prisión, sino que los muestra físicamente impotentes frente al medio en el que se les pone-lo que se opone a la imagen libertadora sugerida en el título. Ana experimenta esta sensación de encierro e impotencia no sólo en la constante prohibición por parte de sus padres de salir o siquiera asomarse a la ventana, sino en su mismo cuerpo cuando es violada por Alirio: “¡Dios mío bendito, ayúdame a zafarme...! Hizo un esfuerzo enorme, pero de pronto algo la sacudió como si fuera una descarga eléctrica, vio todo borroso, todo oscuro, y no supo de más" (183). De hecho, los recuerdos que ella conserva de esa escena son más que todo de una pesadumbre corporal: "no te muevas, pero Ana no podía, aunque hubiera querido, pues se sentía como pasada por trapiche [...] y se levantó con gran esfuerzo, porque tenía el cuerpo magullado" (183). La pesadumbre de su cuerpo en esta experiencia es la más cercana a la dificultad que experimentaría el "pájaro en el agua" al que su discurso recurre varias veces. 
Curiosamente, el evento que termina en su violación es la búsqueda de "nidos de caravanas [...] [que] se ponen furibundas si uno se acerca a los polluelos y muchas veces tenían que tirarse boca abajo porque las caravanas se les lanzaban en picada, las alas desplegadas, con una especie de espolón en las remeras y eran preciosos los huevos, como de gallineto" (180). Aquí, la imagen del pájaro aparece como maternal y protectora, incluso cuando instantes después Alirio se dispone a escuchar la historia de Ana: "ven para acá, debajo de mi alita" (182). Sin embargo, la imagen positiva protectora del pájaro no corresponde con la experiencia de Ana. Al contrario, es a falta de una figura protectora que su "búsqueda de nidos" termina en un abuso sexual: "se oyó la voz de Marcos desde el huerto, y ella rezaba para que al fin viniera alguien, pero la voz de Marcos se alejaba" (ibidem). Aquí el pájaro hace eco de la figura maternal protectora, no por su presencia sino por su ausencia.

Entonces la imagen del pájaro le sirve a Ana para expresar sentimientos de diferente naturaleza: libertad, felicidad, impotencia, encierro. Ana oscila entre la libertad de vuelo del pájaro y la falta de alas o su inutilidad en el medio que la rodea. Ese mismo vaivén o ambigüedad que la imagen del pájaro representa en la vida de Ana, particularmente su experiencia corporal, lo que Hélène Cixous explica cómo el gesto de la mujer. En Le rire de la Méduse (2010), Cixous explica la ambigüedad de los verbos (homónimos en francés) voler: volar y robar. En realidad, más que una desambiguación, Cixous explica que volar es el característico gesto de la mujer, pero este gesto de volar, más que la acción física de moverse de un espacio a otro, es el de robar. Para Cixous la mujer debe robar su libertad, arrebatársela al medio. Para ella, la mujer es como el ave y como el ladrón. Voler es el gesto de la mujer; ella se roba el lenguaje y lo hace volar.

No es una coincidencia: la mujer se parece al ave y al ladrón como el ladrón se parece a la mujer y al ave: pasan, giran, entierran el orden del espacio, desorientan, cambian lugares muebles, cosas, valores, rompen, vacían estructuras, alteran la limpieza. ¿Qué mujer no ha robado ni volado? (Cixous, citada en Osorio 73). 
Así, la identificación corporal que Ana siente con la figura del pájaro, le sirve para expresar por una parte las limitaciones físicas o morales que le impone su entorno y la experiencia de agresión e impotencia de su vida sexual como mujer. Por otra parte, la figura de pájaro también habla de la libertad que Ana "le roba" a su entorno como cuando rompe las reglas del colegio o de su casa: "y es la señal para salir desaforadas. Los pasos persiguiéndola, y la risa que la azuza, ¡a que te cojo ratón! ¡a que no, gato ladrón!, y al fin alcanza la valla del solar de don Cleto de primera: igané!" (20). Los momentos que Ana recuerda como los más felices son aquellos en los que "se vuela," o "canta" como un pájaro.

La imagen de pájaro introducida desde el título de la novela representa en su vuelo el camino que Ana recorre desde su infancia hasta su adultez. En este vuelo, Ana aprende a conocerse a sí misma y la historia de su país, pero sobre todo, es en la corporalidad del ave que Ana encuentra un objeto correlato para verbalizar las sensaciones o situaciones que no entiende. En "la pájara" se articulan imágenes y significados diferentes y hasta contradictorios, pero no es solamente este animal o esta forma de naturaleza que Ángel emplea en la construcción de su narrativa. La pájara es casi exclusiva a la experiencia de Ana, pero hay otros elementos de la naturaleza (como el río y los árboles) que Ángel trae en la construcción de su narrativa y que también contribuyen a representar la magnitud de la Violencia. Este artículo no se ocupará de estos elementos, pero si abre la invitación a leer esta novela desde este ángulo para descubrir cómo los paisajes rural y urbano dejan de ser el trasfondo y se convierten en objetos correlato que reflejan la pluralidad de la violencia, y su impacto en la población femenina.

\section{Conclusión}

Las narrativas traumáticas no son sólo una respuesta a los horribles acontecimientos, sino también un medio para transmitir la brutalidad sufrida por las víctimas. Estas narraciones sirven para mantener la memoria viva y exigen una postura responsable de la sociedad. Por esta razón, el trauma psicológico reflejado en obras literarias pertenecientes a una comunidad o grupo que comparte una historia común de sufrimiento es clave para entender sus voces y sus experiencias. Estaba 
la Pájara Pinta Sentada en el Verde Limón encarna este interés por la voz de la víctima, por una historia más subjetiva. La novela sugiere que el presente es inteligible sólo a través de una recuperación integral del pasado, un proyecto que no deja de ser imposible, pero que Albalucía elabora a través de la temporalidad, el cuerpo femenino y ciertos elementos naturales.

Así, la temporalidad en La Pájara Pinta es dislocada no solo para representar la memoria infantil del personaje principal, sino para reconstruir con esos fragmentos la memoria privada del adulto y la memoria pública de su nación. Esta dislocación de tiempos gramaticales y puntos focales les da voz y autonomía a las víctimas - en este caso la mujer del campo colombiano- para recontar la historia. Con esto, la deconstrucción del tiempo reta el discurso oficial político y literario que invita al olvido o que se concentra en las ciudades y la experiencia masculina de este periodo.

En cuanto a la corporalidad, el cuerpo femenino se ve fracturado, torturado, reducido a su sexo, o simplemente ausente. Para encarnar el dolor, la opresión y la búsqueda de identidad de estos personajes hundidos en un periodo tan violento, Ángel presenta cuerpos que duelen o que no se pueden mover. En ambos casos, la violación o mutilación de los cuerpos se da por razones personales o políticas, y siempre de la mano del sexo opuesto. Sin embargo, Ángel les da voz y memoria, convierte esos cuerpos en espacio político y subversión.

En la brevedad de este estudio, lo espacial se limitó al estudio de algunos elementos naturales como el pájaro, como correlato objeto de las experiencias corporales y psíquicas de la mujer enmarcada en esta época. Sin embargo, la novela también se vale de una descripción del paisaje natural para crear un ambiente violento, deforme y capaz de comprender las ambigüedades y contradicciones de esos períodos históricos. Cada paisaje habla por sus víctimas. Ángel desvela en la ciudad las atrocidades de violencia pública y en el campo la violencia doméstica a la que la mujer es sometida en nombre de disputas patriarcales y políticas.

En la Pájara Pinta los elementos naturales y geoespaciales marcan los espacios políticos y la liminalidad a la que la historia condena a estas 
víctimas. Este ángulo de análisis, aunque mencionado en este artículo, merece un capítulo aparte y evidencia una vez más la riqueza de la narrativa. Tal como lo propone Hallbachs, "every collective memory unfolds within a spatial framework" (140), Ángel evidencia que el entendimiento de la historia y de la gente que la vivió está latente en la relación innegable y recíproca que este pueblo mantiene con su espacio natural y urbano: "place and group have each received the imprint of the other. Therefore every phase of the group can be translated into spatial terms, and its residence is but the juncture of all these terms." (130), y esta novela lo hace a través de la dualidad campo-ciudad que a su vez le da cuerpo a la realidad mujer-hombre.

Para concluir, podemos decir entonces que Estaba la Pájara Pinta Sentada en el Verde Limón, pese a ser a veces subestimada en su género, es una obra riquísima en historia, hábil en estilo, y profunda en su temática. La novela funciona como un artefacto mnemónico que se rehúsa a olvidar, que recrea los cuerpos de sus víctimas y sus hábitats, que emula el dolor, el caos y la ignorancia de un pueblo, que propone otra forma de acceder a su Historia. Ángel reta la Historia, la desbarata y la re-construye, pero también nos muestra la imposibilidad de una verdadera literatura sin ella. Además de la lectura aquí propuesta y de los ángulos de interpretación insinuados, la novela de Ángel no ha sido explorada hasta sus límites, y este artículo es una invitación a descubrir los variados niveles de interpretación que esta narrativa ofrece, y su valor frente a una Historia política y literaria que se ha olvidado de ella. 


\section{Referencias}

Ángel, Albalucía. Estaba la Pájara Pinta sentada en el verde limón. Medellín: Universidad de Antioquia, cop. 2003. Impreso.

Blau, Rosie. "How 9/11 Changed Fiction: After the Unthinkable." The Economist. Sept 2, 2011, www.economist.com/blogs/prospero/2011/09/how911-changed-fiction. Digital.

Butler, Judith. "Performative acts and gender constitution: an essay in phenomenology and feminist theory" Dec., 1988. Jstor. Theatre Journal, Vol. 40, No. 4. 519-531 The Johns Hopkins University Press, http://www.jstor.org/ stable/3207893. Digital.

Ganteau, Jean-Michel. Contemporary trauma narratives: Liminality and the ethics of form. London: Routledge, 2014. Impreso.

Gibbs, Allen. Contemporary american trauma narratives. Edinburgh: Edinburgh University Press Ltd, 2014.Impreso.

Gladhart, Amalia. « Memory private and public: Albalucía Ángel's Estaba La Pájara Pinta sentada en el verde limón »Confluencia, vol. 17, no. 1, 2001, pp. 91-102. JSTOR, www.jstor.org/stable/27922827.Digital.

González-Rodas, Publio. "Léxico de la violencia en Colombia." Hispania, vol. 51, no. 2, 1968, pp. 302-309. JSTOR, www.jstor.org/stable/338512. Digital.

Gutiérrez M., Aleyda. "Propuesta narrativa de Albalucía Ángel en Estaba la pájara pinta sentada en el verde limón."Estudios de Literatura Colombiana, no. 21, 2007, pp. 73-91. Editorial Universidad de Antioquia. https://www. redalyc.org/articulo.oa?id=498357113003. . Digital.

Halbwachs, Maurice, y Lewis A. Coser. On collective memory. 1992. Impreso.

Herman, Judith Lewis. Trauma and recovery: The aftermath of violenceFrom domestic abuse to political terror. New York: Basic Books, 1992-1997. Impreso.

Jaramillo, María Mercedes, et al. Ed. "Albalucía Ángel: El discurso de la insubordinación y las mujeres" Ensayos Sobre Literatura Colombiana. Medellín: U de Antioquia, 1991. 203-38.Impreso.

Mejia, Esteban Carlos. "La Pájara Pinta y el Verde Limón.”El Espectador. 9 Abril 2010 http://www.elespectador.com/opinion/la-pajara-pinta-y-el-verdelimon-columna-197587.Digital.

Osorio, Myriam. Agencia narrativa, agencia femenina: una lectura feminista de la obra en prosa de Albalucía Ángel. Suisse: Peter Lang, 2010.Impreso.

Tobar Torres, Jenner Alonso. "Violencia política y guerra sucia en Colombia. Memoria de una víctima del conflicto colombiano a propósito de 
las negociaciones de La Habana" Memoria y Sociedad 19, no. 38 (2015): 1124. http://dx.doi.org/10.11144/Javeriana.mys19-38.vpgs. Digital.

Vickroy, Laurie. Trauma and survival in contemporary fiction. Charlottesville: University of Virginia Press, 2002.Impreso.

Whitehead, Anne. Trauma fiction. Edinburgh: Edinburgh University Press, 2004.Impreso. 